\section{O sistema de radiodifusão nos 100 primeiros dias do governo Bolsonaro}

\author{
The broadcasting system in the \\ first 100 days of the Bolsonaro \\ government
}

\section{polítıca}

revista compolítica

2020, vol. 10(1)

compolitica.org/revista

ISSN: 2236-4781

DOI: 10.21878/compolitica.2020.10.1.292

(2) Open Access Journal

\author{
Marcio de Souza Castilho \\ Universidade Federal Fluminense \\ [Fluminense Federal University]
}

\begin{abstract}
Resumo
O artigo tem o objetivo de examinar as ações governamentais nos primeiros 100 dias da gestão do presidente Jair Bolsonaro no tocante às políticas de comunicação. A pesquisa se apoia na análise de atos, decretos e portarias publicados no Diário Oficial da União, no período de $1^{\circ}$ de janeiro a 10 de abril de 2019. Em diálogo com as contribuições trazidas por autores na área da Economia Política da Comunicação, buscamos extrair algumas reflexões preliminares sobre a nova estrutura de comunicação do governo, o papel da Empresa Brasil de Comunicação e o direcionamento adotado no sistema de radiodifusão pública. O estudo aponta para o aparelhamento governamental na EBC e permanências da lógica de criminalização de rádios comunitárias, causando prejuízos ao princípio da complementaridade entre os sistemas privado, público e estatal.
\end{abstract}

Palavras-chave: democracia, políticas de comunicação, radiodifusão pública.

\begin{abstract}
This article aims at examining the governmental actions in the first 100 days of office of president Jair Bolsonaro in what concerns communication policies. The research is based on the analysis of acts, decrees and ordinances published on the Diário Oficial da União, from 1st January to 10th April 2019. In concord with contributions brought to light by authors in Communication Political Economy, we have searched to extract some preliminary reflections on the government's new communication structure, the role of Empresa Brasil de Comunicação and the direction adopted by the public broadcasting system. This study points towards a governmental rigging of EBC and the constancy of the logics of criminalization of communitary radios, causing an impairment of the principle of complementarity between the private, public and state services.
\end{abstract}

Keywords: democracy, communication policies; radio broadcast. 


\section{O sistema de radiodifusão nos 100 primeiros dias do governo Bolsonaro}

Marcio de Souza CASTILHO

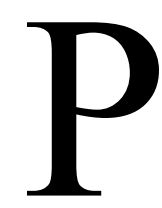

ara marcar o alcance de 100 milhões de pessoas em sua audiência média diária, a Globo produziu em outubro de 2017 uma campanha publicitária "Milhões de uns". Na ocasião, a empresa anunciou que, no acumulado de um mês, o índice chegava a 190 milhões de brasileiros "ou 95\% das pessoas com TV em casa no Brasil"1. O lançamento da campanha institucional da emissora coincidiu com a publicação do Media Ownership Monitor, um estudo conduzido pela organização Repórteres sem Fronteiras e o coletivo Intervozes (2018), demonstrando que, dos 11 países pesquisados, o Brasil apresenta o cenário mais grave em relação aos indicadores de risco à pluralidade da mídia, dentre eles a concentração da audiência, a propriedade cruzada, a falta de transparência sobre os controladores e o direcionamento político do financiamento.

O trabalho de pesquisa envolveu 50 veículos de quatro segmentos (TV, rádio, mídia impressa e online) pertencentes a 26 grupos de comunicação. O monitoramento apontou que Globo, SBT, Bandeirantes e Record concentram audiência superior a 70\% na televisão aberta, sendo que os produtos que constituem o conglomerado de comunicação do Grupo Globo - TVs aberta e por assinatura, rádios, mídias online, jornais, revistas, agência de notícias e segmentos no mercado fonográfico, cinematográfico e editorial têm alcance médio superior às audiências somadas do $2^{\circ}, 3^{\circ}, 4^{\circ}$ e $5^{\circ}$ maiores grupos de comunicação no Brasil. Ao analisar a campanha "Milhões de uns", o Media Ownership Monitor conclui: "O que para o grupo é propaganda do seu alcance, para a pluralidade na mídia pode ser visto como um cenário muito preocupante" ${ }^{2}$.

\footnotetext{
1 Disponível em https://redeglobo.globo.com/novidades/noticia/globo-celebra-alcance-de-mais-de-100milhoes-de-pessoas-por-dia.ghtml

${ }^{2}$ Disponível em

http://brazil.mom-rsf.org/fileadmin/rogmom/output/brazil.mom-rsf.org/brazil.mom-rsf.org-pt.pdf
} 
Os dados reforçam a necessidade de um amplo debate na sociedade para construção de um marco regulatório no campo da comunicação de modo a mitigar o problema da concentração da propriedade dos meios de comunicação no Brasil, reduzindo inclusive a influência de um número reduzido de famílias - os "donos da mídia" - que transmitem concessões públicas de emissoras de rádio e TVs abertas para as gerações vindouras. A democratização da comunicação passa pelo cumprimento dos artigos dispostos, porém não regulamentados, na Constituição de 1988, em seu Capítulo V. Foi a primeira vez que uma Carta Magna expressou uma preocupação pelo direito à comunicação numa tentativa de impedir a formação de monopólios e oligopólios, de incentivar a produção independente e a regionalização das produções cultural, artística e jornalística e de observar o princípio da complementaridade entre os sistemas público, privado e estatal, dentre outros pontos.

O artigo tem o objetivo de examinar as ações governamentais nos primeiros 100 dias da gestão do presidente Jair Bolsonaro no tocante às políticas de comunicação. Para proceder à análise, resgataremos as contribuições trazidas por autores na área da Economia Política da Comunicação (Kucinski; Lima, 2009; Moraes, 2011; Santos, 2006). A outra etapa da pesquisa envolve a consulta às edições do Diário Oficial da União (DOU), no período de $1^{\circ}$ de janeiro a 10 de abril de 2019. A busca se concentra nos atos, decretos e portarias publicados pela Secretaria de Governo da Presidência da República, à qual está subordinada a Secretaria Especial de Comunicação Social, e pelo Ministério da Ciência, Tecnologia, Inovações e Comunicações (MCTIC), cuja estrutura contempla a Agência Nacional de Telecomunicações (Anatel) e a Secretaria de Radiodifusão.

A partir do diálogo entre o arcabouço teórico e a análise de dados, buscaremos extrair algumas reflexões preliminares sobre a nova estrutura de comunicação do governo, o papel da Empresa Brasil de Comunicação (EBC) e o direcionamento adotado no sistema de radiodifusão. A análise será complementada com a pesquisa de fontes secundárias, como artigos, relatórios e material jornalístico. 


\section{A Constituição de 1988: obstáculos à regulamentação}

Os serviços de radiodifusão no Brasil compreendem estações radiodifusoras de som e imagem, incluindo rádio (Frequência Modulada, Onda Média, Onda Curta, Onda Tropical, Radiodifusão Comunitária), emissoras e retransmissoras de televisão, além de Serviços Auxiliares de Radiodifusão e Correlatos, com limites de permissões e concessões por entidade estabelecidos pelo Estado brasileiro. Os dados sobre o número total de emissoras de radiodifusão não estão sistematizados, sendo apresentados de forma segmentada por parte do Ministério da Ciência, Tecnologia, Inovações e Comunicações (MCTIC) e da Agência Nacional de Telecomunicações (Anatel). A Associação Brasileira de Emissoras de Rádio e Televisão (Abert) consolidou alguns números referentes a 2013 a partir dos levantamentos oficiais. A entidade divulgou, na ocasião, que o país tinha 9.589 emissoras de rádio, sendo 4.619 de cunho comercial, 466 educativas e 4.504 comunitárias. Emissoras de televisão, com portaria de autorização naquele ano, totalizavam 517, das quais 317 eram comerciais e 204, educativas. Já o número de retransmissoras atingia $10.470^{3}$.

O Artigo 220 da Constituição dispõe, em seu parágrafo $5^{\circ}$, que os "meios de comunicação não podem, direta ou indiretamente, ser objeto de monopólio ou oligopólio" (Brasil, 2016). Apesar do quantitativo de emissoras de rádio e televisão aberta existentes no Brasil, a falta de regulamentação do dispositivo permite que um mesmo grupo de comunicação estabeleça as diretrizes e políticas editoriais com alcance em todo o território nacional, através do seu sistema de afiliadas, tornando inócua a legislação que limita o número de concessões a que um mesmo proprietário tem direito. Os maiores conglomerados de mídia no Brasil, como vimos, contam ainda com jornais, revistas, portais na internet e outros suportes. Por esse motivo, setores organizados da sociedade civil que atuam no campo da democratização da comunicação buscam fortalecer o debate sobre a importância da regulação para combater a propriedade cruzada, pois entendem que, mesmo com a multiplicidade de canais, há uma uniformidade na programação e homogeneização das pautas. Nesse sentido, a regulação vigente "legou ao conjunto da

\footnotetext{
${ }^{3}$ Disponível em https://www.abert.org.br/web/index.php/dados-do-setor/estatisticas/radiodifusao-licencas-e-outorgas
} 
população um sistema com baixa diversidade de fontes de informação e pouca pluralidade de vozes" (Vilela, 2018, p. 47).

Apesar de a Carta de 1988 prever uma distribuição equitativa na estrutura da radiodifusão, "observado o princípio da complementaridade dos sistemas privado, público e estatal", conforme dispõe o artigo 223 (Brasil, 2016), a mídia privada de interesse comercial tem predominância em relação aos outros dois atores. Os critérios adotados para a destinação dos recursos da publicidade governamental vêm privilegiando, nas últimas décadas, as organizações empresariais em detrimento dos veículos públicos e comunitários. O chamado "critério técnico", baseado em estratégias de mercado, considerando o fator audiência, está expresso mais recentemente na Instrução Normativa (IN) da Secretaria de Comunicação da Casa Civil da Presidência da República, de 19/12/2014. Ao estabelecer as diretrizes para o planejamento das ações de mídia, a IN define, em seu artigo $8^{\circ}$, que "investimentos destinados a cada veículo devem considerar as respectivas audiências, embasados, sempre que possível, em dados técnicos de mercado, pesquisas e/ou estudos de mídia".

Mattelart inclui o espectro das frequências de radiodifusão no conjunto dos bens públicos comuns, tal como a educação, a saúde e o meio ambiente, "domínios que deveriam constituir 'exceções' à lei do livre comércio, 'coisas' às quais as pessoas e os povos têm direito, produzidas e repartidas em condições de liberdade e equidade" (Mattelart apud Moraes, 2011, p. 57). Uma das características centrais do sistema de radiodifusão pública no Brasil - o controle político das concessões de rádio e TV - restringe, no entanto, as possibilidades de uma comunicação participativa, plural e cidadã, percebida como um direito humano. Para além do debate sobre a aliança formada entre empresários de mídia e o campo político na construção de consensos em torno da agenda conveniente ao modelo hegemônico neoliberal, a falta de regulação torna permissivas as relações entre concessionários e poder concedente.

No parágrafo $3^{\circ}$ do dispositivo constitucional supracitado, está expresso que o "ato de outorga ou renovação somente produzirá efeitos legais após deliberação do Congresso Nacional" (Brasil, 2016), ou seja, os congressistas são responsáveis pelos atos de outorga e renovação de concessões e permissões de radiodifusão. Ocorre, porém, que muitos 
parlamentares, na Câmara dos Deputados e no Senado Federal, detêm direta ou indiretamente a propriedade de emissoras de rádio e TV, configurando conflito de interesses. A organização Transparência Brasil, através do projeto "Excelências", divulgou que, na última legislatura (2015-2019), pelo menos 43 deputados e 19 senadores eram concessionários, representando $10 \%$ do Congresso Nacional ${ }^{4}$. A prática fere o artigo 54 da Constituição, que proíbe a propriedade dos meios de radiodifusão por deputados e senadores.

O controle político também costuma ser exercido em comissões especiais no Congresso criadas especificamente para tratar do processo de outorgas na radiodifusão. A composição dessas comissões costuma incluir os parlamentares concessionários como assíduos representantes, tornando o processo de renovação das licenças praticamente automático, sem "qualquer tipo de fiscalização, a não ser a burocrática" (Kucinski; Lima, 2009, p. 112).

Ainda em relação ao capítulo concernente à comunicação social, Kucinski e Lima (2009) criticam o parágrafo $4^{\circ}$ do artigo 223, que impede o Poder Executivo de suspender concessões em caso de descumprimento de contrato. A Carta de 1988 estabelece que o "cancelamento da concessão ou permissão, antes de vencido o prazo, depende de decisão judicial" (Brasil, 2016). Para os autores, o dispositivo mostra uma "assimetria" entre as diferentes concessões pois "em qualquer outro serviço público que a União concede transporte rodoviário, aéreo, ferroviário, energia, o que seja -, quando o contrato não está sendo cumprido, ela tem a prerrogativa de suspendê-lo" (Kucinski; Lima, 2009, p. 118). A radiodifusão constitui, portanto, uma exceção neste cenário, demonstrando a centralidade da comunicação e sua apropriação por empresários e grupos políticos no país.

Desde a redemocratização, a distribuição de outorgas de canais de rádio e TV foi usada como "moeda política" por parte de sucessivos governos. Na gestão de José Sarney, a primeira após 21 anos de ditadura civil-militar (1964-1985), a negociação envolvendo

\footnotetext{
${ }^{4}$ Outros parlamentares, conforme revelou o estudo, mantinham influência na linha editorial de veículos de comunicação de abrangência local ou regional a partir do uso de testas-de-ferro ou familiares no comando dessas emissoras (Intervozes, 2016).
} 
concessões de radiodifusão a parlamentares influenciou diretamente na votação para ampliação do mandato presidencial para cinco anos. A prática não arrefeceu nos governos subsequentes de diferentes espectros político-ideológicos, de Fernando Collor de Mello a Dilma Rousseff, passando pelos dois mandatos de Fernando Henrique Cardoso e Luiz Inácio Lula da Silva, em que pese as especificidades de cada contexto histórico. Alguns autores (Motter, 1994; Bayma, 2001; Santos; Caparelli, 2005; Lima, 2005) identificam nestas relações clientelistas e de barganha entre o sistema midiático e o sistema político um tipo de "coronelismo eletrônico", com graves prejuízos à pluralidade de conteúdo e diversidade de vozes no debate público.

\begin{abstract}
Se a terra no coronelismo servia ao coronel como instrumento de ampliação da sua influência, a radiodifusão no coronelismo eletrônico é ainda mais eficiente: serve para difundir a imagem protetora do coronel, serve para controlar as informações que chegam ao eleitorado e serve, por fim, para atacar os inimigos. Estas funções da radiodifusão justificam, para o coronel, a busca do controle desses meios e o cuidado para deixar seus inimigos longe deles (Santos, 2006, p. 21).
\end{abstract}

Grupos liderados por políticos ou famílias com tradição política controlam, nos estados, emissoras de rádio e TV afiliadas às grandes redes. Bandeira (2018) cita como exemplo de "coronelismo eletrônico" o controle da família Magalhães na TV Bahia, afiliada da Rede Globo; da família Collor de Mello, proprietária da TV Gazeta Alagoas, também afiliada daquela emissora; e da família do apresentador de televisão Carlos Massa, cuja rede de televisão é afiliada do SBT no Paraná. Aos atores políticos conhecidos somam-se os segmentos religiosos (católicos e evangélicos) nos últimos anos. As relações entre mídia e religião, como veremos adiante, constituem um elemento importante na atual configuração da radiodifusão brasileira.

O combate à concentração da propriedade dos meios de comunicação no Brasil, a defesa da complementaridade entre os sistemas público, privado e estatal, a definição de regras mais democráticas e transparentes para concessões e renovações de outorgas - com a criação de mecanismos para evitar que políticos, em exercício de mandato eletivo, detenham a posse de canais de rádio e TV - e a garantia de laicidade na exploração dos serviços de radiodifusão foram algumas das mais de 600 propostas apresentadas e aprovadas, em 2009, durante a I Conferência Nacional de Comunicação (Confecom). A 
iniciativa reuniu cerca de 30 mil pessoas, com etapas preparatórias realizadas nas 27 unidades de federação, para discutir e auxiliar o governo na proposição de políticas públicas para o setor. A despeito do boicote promovido na ocasião pelas entidades empresariais, a Conferência representou um momento inédito de participação social na construção de um marco regulatório, com o envolvimento de setores organizados da sociedade civil.

Em 2012, o Fórum Nacional pela Democratização da Comunicação chegou a promover a campanha Para expressar a liberdade, que deu origem a um projeto de lei de iniciativa popular ${ }^{5}$. A chamada Lei da Mídia Democrática reafirma os princípios fundamentais estabelecidos pela Confecom, incluindo a afirmação da comunicação como direito humano, a descriminalização da radiodifusão comunitária e universalização da internet banda larga. O documento também busca regulamentar os artigos 221 e 224 da Constituição, visando, respectivamente, fomentar a produção independente e regional e instituir um Conselho Nacional de Comunicação.

Para Valente (2014), o resultado da Confecom, em termos de execução das ações, pode ser considerado frustrante. Apesar dos esforços dos grupos que compõem a frente em prol da democratização da comunicação, permanece no Brasil, como temos demonstrado, um processo de forte concentração da propriedade dos meios, com todas as suas consequências. $\mathrm{O}$ contexto político atual não indica uma reversibilidade desse quadro.

\section{A Comunicação no novo governo: considerações preliminares}

O capitão reformado do Exército e parlamentar Jair Bolsonaro (Partido Social Liberal) foi eleito presidente da República nas eleições de 2018 com 55,13\% dos votos válidos (57.797.847 votos). Derrotou o acadêmico e advogado Fernando Haddad (Partido dos Trabalhadores), ex-prefeito de São Paulo (2013-2016) e ex-ministro da Educação nos governos de Lula e Dilma Rousseff, que obteve 44,87\% (47.040.906 votos) pela coligação "O povo feliz de novo".

\footnotetext{
${ }^{5}$ Disponível em: <http://www.paraexpressaraliberdade.org.br/>. Acesso: 14 março 2019.
} 
Na proposta de governo durante campanha, divulgada no Sistema DivulgaCandContas do Tribunal Superior Eleitoral (TSE), a coligação vitoriosa "Brasil Acima de tudo, Deus acima de todos" faz menção ao tema da comunicação em um único slide, com cinco tópicos, denominado "Imprensa livre e independente" ${ }^{6}$. Nesta apresentação, seus representantes destacam ser "defensores da liberdade de opinião, informação, imprensa, internet, política e religiosa!", opondo-se a "qualquer regulação ou controle social da mídia". Os demais tópicos são vagos, não indicando políticas objetivas no campo da comunicação, especificamente na radiodifusão pública. Descreve o documento: "Liberdade das pessoas e de suas famílias em poder escolher os rumos da vida na contínua busca da felicidade!". Em outro tópico: "A liberdade é o caminho da prosperidade. Não permitiremos que o Brasil prossiga no caminho da servidão".

\section{Estrutura da Secretaria de Governo}

Bolsonaro e o vice-presidente, Hamilton Mourão, general da reserva do Exército, assumem em $1^{\mathrm{o}}$ de janeiro de 2019. O governo edita a Medida Provisória $\mathrm{n}^{\mathrm{o}} 870$, reorganizando a estrutura dos órgãos da Presidência da República e dos ministérios. A Secretaria de Governo, à qual está subordinada a Secretaria Especial de Comunicação Social (Secom), fica sob a responsabilidade do ministro Carlos Alberto dos Santos Cruz, também general da reserva do Exército. Para a Secom, após passagem do publicitário Floriano Barbosa de Amorim Neto, que atuava no gerenciamento das redes sociais do deputado federal Eduardo Bolsonaro (PSL-SP), o presidente nomeia o empresário Fábio Wajngarten para a chefia daquela secretaria, antes mesmo de o governo completar 100 dias. Wajngarten atuava no setor de pesquisa de mídia. Já como porta-voz do Palácio do Planalto, é designado outro general do Exército, Otávio do Rêgo Barros, a quem cabe fazer a comunicação dos atos do presidente aos jornalistas.

Em relação à Secretaria de Governo, a MP 870/2019 formaliza a criação de cinco secretarias especiais, a saber: de Articulação Social, de Comunicação Social, do Programa

\footnotetext{
${ }^{6}$ Disponível em http://www.tse.jus.br/imprensa/noticias-tse/2018/Outubro/eleicoes-2018-justica-eleitoralconclui-totalizacao-dos-votos-do-segundo-turno
} 
de Parcerias de Investimentos, de Relações Institucionais e de Assuntos Federativos, além do Gabinete, da Secretaria-Executiva e da Assessoria Especial. A implantação da política de comunicação e de divulgação social do Executivo Federal, a relação com os jornalistas em eventos com a participação do presidente, a realização de pesquisa de opinião pública e a normatização e supervisão dos contratos de publicidade e patrocínio estatal, dentre outras atividades, estão entre as atribuições da pasta.

Em seu artigo $5^{\circ}$, inciso II, a MP também estabelece que compete à Secretaria de Governo "supervisionar, coordenar, monitorar e acompanhar as atividades e as ações dos organismos internacionais e das organizações não governamentais no território nacional" (Brasil, 2019). A medida gerou reação imediata de movimentos e entidades da sociedade civil. Uma carta aberta enviada ao ministro Santos Cruz, assinada por 65 organizações, em janeiro de 2019, questionou a constitucionalidade da decisão do governo sustentando que "a existência de uma sociedade civil plural, atuante e autônoma é essencial para a qualidade da democracia" ${ }^{7}$. Nos mesmos termos da carta encaminhada ao ministro, a Rede Sustentabilidade entrou em fevereiro com uma Ação Direta de Inconstitucionalidade (Adin), com pedido de medida cautelar, para apreciação do Supremo Tribunal Federal (STF) contra a MP 870/2019, contestando a "interferência governamental em atividades associativas" ${ }^{8}$.

Importa ressaltar que compartilhamos os valores defendidos na declaração "O direito de informar e ser informado" sobre o papel do Estado em relação às políticas de comunicação. A carta, divulgada por ocasião da Assembleia pelo Direito à Comunicação, durante o Fórum Social Mundial de 2011, em Dakar, Senegal, entende o Estado como "instituição que pode salvaguardar a diversidade informativa e cultural enquanto elemento decisivo à afirmação da cidadania, em consonância com reivindicações da sociedade civil" (Moraes, 2011, p. 58). A declaração adota ainda como princípios:

defender, apoiar e promover iniciativas pelo direito à comunicação e à informação como um direito humano fundamental; lutar por um marco regulatório e legislativo para as mídias públicas, alternativas e

\footnotetext{
${ }^{7}$ Disponível em https://www.pactopelademocracia.org.br/blog/carta-ao-ministro.

${ }^{8}$ Disponível em https://s3-sa-east-1.amazonaws.com/rs-arquivos-uteis/ADI+-+MP+870+-+REDE.pdf
} 
comunitárias, garantindo o exercício do direito à comunicação, inclusive através do acesso a frequências de radiodifusão; criar e reforçar as sinergias entre todos os sujeitos da transformação social; promover o acesso, a acessibilidade e a apropriação das mídias e das novas tecnologias de informação e comunicação por todos os cidadãos, sem restrição de gênero, classe, raça ou etnia (...); apoiar o desenvolvimento das mídias comunitárias e alternativas; combater a censura e garantir a liberdade de expressão na internet; discutir modelos de financiamento que garantam a visibilidade, a sustentabilidade e a independência dos veículos alternativos (Moraes, 2011, p. 58/59).

\section{O papel da $E B C$}

A MP 870/2019, inciso IX, descreve que compete ao órgão chefiado pelo ministro Santos Cruz "coordenar a implementação e a consolidação do sistema brasileiro de televisão pública" (BRASIL, 2019). Embora não tenha havido uma sinalização clara por parte do atual governo sobre quais serão as diretrizes desse novo modelo, uma portaria assinada em 09/04/2019 por Alexandre Henrique Graziani Jr., diretor-presidente da Empresa Brasil de Comunicação (EBC), compromete a experiência de uma TV pública no país. A portaria estabelece a fusão da programação da TV Brasil, emissora pública pertencente à EBC, e da TV Nacional Brasil (NBR), criada em 1998 como canal estatal para dar transparência aos atos do Poder Executivo. O documento afirma preservar o princípio constitucional "da complementaridade dos sistemas público e estatal" - o artigo 223 da Constituição destaca a observância dos sistemas privado, público e estatal - porém cita o dispositivo para descumpri-lo ao misturar as fronteiras entre o público e estatal, que apresentam características distintas.

A criação da empresa pública federal, em 2008, durante o segundo mandato do governo Lula, abriu ampla discussão sobre o papel da radiodifusão pública. Foi a primeira tentativa mais estruturada de um sistema público de comunicação no Brasil. Em outros países, conforme demonstrado em estudos comparativos (Intervozes, 2009; Mendell, 2011; Pieranti, 2018), a consolidação desse sistema, com independência em relação a mercados e governos, fontes estáveis de financiamento e fortalecimento de mecanismos de controle e participação da sociedade civil, permitiu a pluralidade de pontos de vista e a diversidade de oferta de conteúdos de interesse público. Para os autores, superados os desafios de ordem política, financeira e estrutural, a experiência das emissoras de serviço público de 
radiodifusão ou "mídia pública" (Intervozes, 2009) tem sido essencial, em última instância, para o aperfeiçoamento do processo democrático.

Pieranti (2018), ao explicitar a importância social da radiodifusão pública, observa que esta exerce um papel complementar, seja em relação ao sistema privado que, embora classificado como serviço público, objetiva o lucro, seja em relação ao sistema estatal. Para o autor, cabe às emissoras públicas contemplar um tipo de conteúdo não veiculado, por exemplo, pela mídia comercial, como as produções independentes e educativas. Ele observa que

\begin{abstract}
o sistema público é de responsabilidade de entidades públicas, porém sujeitas a mecanismos de governança permeados por atores externos ao Estado; conta com fontes de financiamento que vão além do orçamento público; e sua programação, orientada por valores como a construção da cidadania e a promoção do debate público, não se confunde nem com conteúdos institucionais de governo, nem com aqueles cujo foco central é a simples busca de audiência. Além disso, a radiodifusão pública deve se manter equidistante, do ponto de vista editorial, das demandas de governos e mercados, buscando a audiência como consequência natural de uma programação independente, crítica e menos superficial" (Pieranti, 2018, p. 28/29).
\end{abstract}

No caso brasileiro, a formação de um Conselho Curador na recém-criada EBC, com integrantes da sociedade civil, visava possibilitar maior representatividade de segmentos historicamente excluídos do debate público, como os movimentos negro, indígena e de gênero, dentre outros. Na ocasião, o então ministro da Comunicação Social, Franklin Martins, explicava a diferença entre os três sistemas, destacando que a TV Brasil privilegiaria a comunicação pública.

Não é uma TV que vai ficar fazendo comunicação do governo, jornalismo chapa branca e procurando passar os pontos de vista do governo para a sociedade. É uma TV pública, no sentido de que ela não vai se guiar pela lógica comercial. Isso significa que ela não precisa reunir, perseguir e manter altíssimos índices de audiência (...). A televisão pública pode experimentar e reunir os vários Brasis dentro dela. E fazer o que se faz no mundo todo: uma TV que tenha cultura, jornalismo isento, debates aprofundados de vários assuntos, aberta à produção independente e regional (Martins, apud Moraes, 2009, p. 195).

Quando foi fundada, a EBC incorporou os canais de rádio e TV geridos pela estatal Radiobras. Através da Lei $n^{\circ}$ 11.652/2008, foi implantada também a TV Brasil. Apesar 
da criação de um conselho curador, a independência editorial e a autonomia para definir produção, programação e distribuição de conteúdo nunca foram plenamente alcançadas, nem nos primeiros anos de funcionamento da TV Brasil (Moraes, 2009). Outros princípios previstos na mesma Lei $11.652^{9}$, que dispõe sobre os serviços de radiodifusão pública, também não se efetivaram na prática. As limitações ocorreram, em parte, pela demasiada centralização legal na figura do presidente da República, a quem cabia nomear a Diretoria Executiva, os cinco membros do Conselho de Administração e os 20 membros do Conselho Curador.

Mendell (2011) salienta a importância de um arcabouço jurídico bem elaborado para a radiodifusão pública mas adverte que a normatização legal per si não é suficiente para a autonomia das emissoras, a regularidade do financiamento e a prestação pública de contas. "Esses elementos devem ser complementados por um engajamento ativo por parte do poder público e da sociedade civil" (Mendell, 2011, p. 96).

Com a alteração da estrutura da EBC pela Lei 13.417/2017, na gestão de Michel Temer (MDB), o caráter público dos produtos da empresa pública foi cedendo espaço para um tipo de programação mais afeita aos interesses governamentais. Pelas novas normas, o Conselho Curador foi extinto, reservando à Diretoria Executiva, sem participação de organizações da sociedade civil, a responsabilidade pela linha editorial dos programas. A lei também extinguiu a regra que previa mandato de quatro anos para o diretor-presidente, não coincidindo com o mandato do presidente da República. Na versão final da Lei 13.417, o gestor da EBC pode ser substituído a qualquer momento, a depender da decisão de quem ocupa a chefia do Executivo federal.

O aparelhamento da empresa pública pelo poder estatal se aprofunda no governo Bolsonaro com a recente portaria que funde a programação da TV Brasil e da NBR. A

\footnotetext{
${ }^{9}$ A lei instituiu os princípios e objetivos dos serviços de radiodifusão pública, dentre eles destacamos no art. $2^{\circ}$ : "II - promoção do acesso à informação por meio da pluralidade de fontes de produção e distribuição do conteúdo; III - produção e programação com finalidades educativas, artísticas, culturais, científicas e informativas; IV - promoção da cultura nacional, estimulo à produção regional e à produção independente; autonomia em relação ao Governo Federal para definir produção, programação e distribuição de conteúdo no sistema público de radiodifusão; e IX - participação da sociedade civil no controle da aplicação dos princípios do sistema público de radiodifusão, respeitando-se a pluralidade da sociedade brasileira" (Brasil, 2008).
} 
programação estreou oficialmente em 10/04/2019 com maior inserção de conteúdo das ações do presidente da República e dos ministros, além de programas inteiramente dedicados às Forças Armadas. A reestruturação também confere destaque à Reforma da Previdência, pauta prioritária da equipe econômica do governo, e ao setor do agronegócio. As produções estão sendo conduzidas também por funcionários concursados da empresa. Não obstante, as mudanças impactam a produção jornalística. No dia de lançamento da nova programação, o Repórter Brasil Noite, que passou a ter 45 minutos de duração, exibiu uma entrevista de 13 minutos com o ministro-chefe da Casa Civil, Ônix Lorenzoni. Por decisão editorial, expressões como "golpe" e "ditadura" foram vetadas nas matérias produzidas por repórteres e editores (Barreto, 2019).

A desconfiguração do caráter público da EBC passa também por um princípio de rentabilidade característico da mídia comercial, que associa a qualidade de um canal de televisão a indicadores de audiência. Por diversas vezes, políticos de linha liberalconservadora e o próprio Bolsonaro criticaram o "traço de audiência" da TV Brasil, gerando custos ao Estado brasileiro ${ }^{10}$. Assim, a programação deveria ser planejada e executada seguindo as regras de mercado. No governo Jair Bolsonaro, permanece o primado da lógica privada. No Diário Oficial da União (DOU), de 06 de fevereiro de 2019, a Secretaria de Governo publicou extrato de termo aditivo prorrogando o contrato entre a EBC e a Kantar Ibope Pesquisa de Mídia para medição de desempenho de audiência de rádio. $\mathrm{O}$ valor da prestação do serviço é de $\mathrm{R} \$ 173,4$ mil pelo contrato de um ano, assinado em 29 de janeiro.

\section{Rádios comunitárias}

A transição de governos não tem alterado, do mesmo modo, a política de fiscalização e repressão a rádios comunitárias (RadCom). No último dia do governo Temer, em 31/12/2018, por decisão do então ministro da Ciência, Tecnologia, Inovações e Comunicações (MCTIC), Gilberto Kassab, cerca de 130 emissoras de radiodifusão

\footnotetext{
${ }^{10}$ Entrevista de Jair Bolsonaro a TV Record em 29/10/2019 após ter sido eleito em $2^{\circ}$ turno. Disponível em https://moneytimes.com.br/veja-os-principais-trechos-da-1a-entrevista-de-bolsonaro/ .
} 
comunitária de diferentes regiões do país tiveram as concessões extintas ou as outorgas peremptas. No primeiro caso, as entidades não têm mais autorização para permanecer no ar a partir da publicação no Diário Oficial da União. Diz-se de outorgas peremptas aquelas em que o ato de extinção somente produzirá efeitos legais após deliberação do Congresso Nacional, como determina o artigo 223 da Constituição Federal. As sanções são respaldadas, em grande parte, pelo artigo 40 do Decreto $n^{\circ} 2.615$, de 03/06/98, que regulamenta a Lei no 9.612, de 19/02/98 sobre o serviço de Radiodifusão Comunitária. Mas o arcabouço legal que permite, desde a apreensão de equipamentos até o indiciamento criminal dos comunicadores, é anterior ao golpe de 64, como a Lei 4.117/1962, que institui o Código Brasileiro de Telecomunicações.

Na estrutura do MCTIC, as advertências, multas e revogação da autorização estão sob a responsabilidade do Departamento de Radiodifusão Educativa, Comunitária e de Fiscalização, no âmbito da Secretaria de Radiodifusão. A própria inclusão do termo "Fiscalização" na nomenclatura do órgão que lida com a radiodifusão educativa e comunitária parece remontar a legislação anacrônica que, em 2022, completará 60 anos. É corriqueira, desde o início de janeiro de 2019, a publicação de portarias com algum tipo de penalidade aplicada a entidades de RadCom por descumprimento de exigência legal dentro do prazo estipulado pelo MCTIC, como determina o artigo 40, inciso XXIX, do Regulamento da Radiodifusão Comunitária (Decreto 2.615/98). Outras são autuadas por mudança das características constantes da licença de funcionamento (inciso XXII), não observância do prazo estabelecido para o início da execução do serviço (inciso XXIV) ou não integração a redes para transmissão obrigatória dos poderes Executivo, Legislativo e Judiciário (inciso XII), dentre outras alegações. As rádios comunitárias ainda são impedidas por lei de obter recursos via publicidade, ao contrário do que ocorre com as emissoras comerciais. $\mathrm{O}$ artigo 40, inciso XIV, prevê penalidades caso alguma entidade RadCom faça transmissão de patrocínios.

No governo Bolsonaro, num único dia, o Departamento chegou a aplicar 28 multas a emissoras de rádio, sendo 25 comunitárias, em portaria no Diário Oficial da União, de 20 de março de 2019. Praticamente todas essas sanções baseavam-se no artigo 11 da Lei 9.612/98, que proíbe as entidades mantenedoras de radiodifusão comunitária de 
"estabelecer ou manter vínculos que a subordinem ou a sujeitem à gerência, à administração, ao domínio, ao conteúdo ou à orientação de qualquer outra entidade, mediante compromissos ou relações financeiras, religiosas, familiares, políticopartidárias ou comerciais" (Brasil, 1998).

Observa-se, portanto, um rigor na aplicação das normas legais que não se verifica, por exemplo, no sistema privado de radiodifusão. Para ilustrar este raciocínio, o já mencionado estudo Media Ownership Monitor, da organização Repórteres sem Fronteiras e do coletivo Intervozes, destaca o vínculo de grupos religiosos com a mídia comercial brasileira: de 50 veículos pesquisados, nove eram de propriedade de lideranças religiosas e seis apresentavam conteúdo de denominações religiosas em suas páginas e grades de programação, embora não definidos como religiosos. Um outro levantamento, de 2016, realizado pela Agência Nacional de Cinema (Ancine) e reproduzido pelo Media Ownership Monitor, revelou que a programação religiosa cristã, em suas vertentes católica e evangélica, tornou-se o principal gênero transmitido pelas redes de televisão aberta do país, ocupando $21 \%$ do total da programação. As religiões de matriz africana estão excluídas desse panorama da comunicação no Brasil.

Resta demonstrado, a partir do cruzamento desses indicadores com as sanções aplicadas pela Secretaria de Radiodifusão, o tratamento diferenciado por parte do Poder Executivo na relação com as emissoras de rádio e TV no país. A depender da natureza do veículo, comunitário ou comercial, a lei aplicada para muitos não vale para um círculo restrito de grupos empresariais de comunicação.

É interessante observar que, para além da falta de regulamentação do artigo 220 da Carta, o qual impede, em seu parágrafo $5^{\circ}$, a formação de monopólio e oligopólio, outros instrumentos legais favorecem o processo de concentração da propriedade dos meios de comunicação social. A pesquisa ao DOU, no período definido para a análise, identificou que emissoras de radiodifusão foram enquadradas também no Decreto $\mathrm{n}^{\mathrm{o}} 5.371$, de 17/02/2005, que pode ser interpretado como um incentivo à propriedade cruzada. $\mathrm{O}$ decreto que trata dos serviços de retransmissão e repetição de televisão determina em seu artigo 33, inciso II, que a "inserção de programação local não deverá ultrapassar $15 \%$ do total da programação transmitida pela estação geradora de televisão a que a 
retransmissora estiver vinculada" (Brasil, 2005), limitando, portanto, a produção de conteúdo local e autônomo.

Por fim, as exigências de ordem econômica e burocrática não afetam apenas as emissoras em operação, mas inibem quem pretende obter autorização de funcionamento em território nacional, o que resultaria numa comunicação mais plural, diversa e democrática.

Muitos pedidos de regularização das concessões chegam a tramitar durante décadas, sem resposta efetiva por parte do Governo Federal. Um exemplo é o da Associação Rádio Comunitária São Judas Tadeu, do município de Duque de Caxias, Região Metropolitana do Rio de Janeiro. Desde 2002, a entidade tenta obter a outorga para instalação e funcionamento de uma rádio comunitária. A associação entrou com uma representação junto ao Ministério Público Federal (MPF). Com base neste pedido, o MPF moveu uma ação civil pública, em dezembro de 2018, para que o MCTIC atue com mais celeridade em processos administrativos da São Judas Tadeu e de outras entidades RadCom. Em março de 2019, a Justiça determinou, em liminar, que as apreciações dos pedidos de regularização de funcionamento das emissoras na Baixada Fluminense sejam concluídas no prazo de 120 dias. Na mesma decisão, foi exigida a análise de eventuais novos pedidos no prazo máximo de 12 meses $^{11}$.

\section{Conclusão}

Em meados de fevereiro de 2019, a Secom realizou uma reunião intitulada $1^{\circ}$ Encontro sobre Comunicação Global. Envolveu equipes de comunicação de todas as repartições federais - incluindo ministérios e empresas estatais - para apresentação de diretrizes de divulgação em cada área. A Medida Provisória $n^{\circ} 870$ já havia delineado o novo desenho institucional, com a apresentação da estrutura básica dos órgãos da Presidência e dos ministérios. Na ocasião, a imprensa noticiou que a Secretaria de Governo não tinha,

\footnotetext{
11 Disponível em <http://www.agenciaabraco.org/site/justica-determina-celeridade-a-analise-de-pedidosde-funcionamento-de-radios-comunitarias-na-baixada-fluminense/>. Acesso em: 24 mar. 2019.
} 
contudo, um plano de ações prioritárias e uma política de comunicação definida e coordenada entre os diferentes atores que compõem a administração pública federal.

Acreditamos ser precipitado afirmar que não haja uma política de comunicação. Como procuramos demonstrar, uma visão mais atenta das primeiras ações governamentais revelam que, ao contrário dos rumores quanto à extinção da $\mathrm{EBC}$, a atual gestão decidiu reestruturar a empresa, conferindo-lhe características de sistema estatal em detrimento do caráter público que inspirou a sua criação em 2008. Nesse sentido, o governo aprofunda as mudanças iniciadas ainda no governo do ex-presidente Michel Temer, que, por meio da Lei 13.417/17, decidira extinguir o conselho curador, com a participação da sociedade civil, e pôr fim à regra que previa mandato de quatro anos para o diretor-presidente, não coincidindo com o mandato do presidente da República.

A pesquisa também identificou a manutenção do aparato legal repressivo contra as rádios comunitárias, com sanções previstas em legislações criadas nos anos 1960. O processo de criminalização de RadCom se mantém no atual governo com publicação periódica de portarias aplicando advertência, multa e revogação da autorização de emissoras de rádio em todo o território nacional. Importa notar que o rigor na aplicação da Lei 9.612/98, quanto aos vínculos de mantenedoras de radiodifusão comunitária a grupos religiosos, familiares ou político-partidários, não se verifica na mídia comercial. Foi possível observar ainda que as exigências de ordem burocrática não se limitam às entidades em operação, mas dificultam sobremaneira o início de atividade daqueles comunicadores que entram com pedido de regularização. Muitas solicitações percorrem os gabinetes do Ministério das Comunicação - atual MCTIC - durante décadas, sem uma conclusão por parte do poder público federal.

A relação que o novo governo vem estabelecendo com a sociedade, através de suas políticas de comunicação, abre espaço para um vasto repertório de questões. Não desconsideramos a importância do recorte que privilegia, por exemplo, a análise sobre o intenso uso das redes sociais pela família Bolsonaro. Ferramentas digitais foram suportes estratégicos para o êxito da candidatura do PSL na campanha presidencial e fornecem, sem dúvida, um campo de exploração amplo para futuras pesquisas dada a centralidade do Twitter e do WhatsApp como instrumento de comunicação institucional do Palácio do 
Planalto. Contudo, optou-se por examinar neste artigo a nova estrutura da Secretaria de Governo, pasta à qual está subordinada a Secom, e as ações que atingem diretamente o sistema de radiodifusão pública.

A resposta de diferentes organizações em torno da fiscalização de ONGs como atribuição da Secretaria de Governo demonstra a necessidade de participação da sociedade civil como instrumento de pressão e de produção de contrassentidos às decisões governamentais no campo da comunicação. Se o cenário para o debate em torno da criação de um marco regulatório se mostra improvável nas circunstâncias políticas atuais, o monitoramento das ações é fundamental, ao nosso ver, para a defesa da complementaridade dos sistemas privado, público e estatal, conforme determina a Constituição de 88. No governo atual, o sistema público está ameaçado com o aprofundamento de uma política que não o distingue do estatal e as permanências de uma lógica coercitiva que vem limitando a possibilidade, na radiodifusão, de uma comunicação plural e aberta a outras possibilidades enunciativas.

\section{Referências}

BANDEIRA, O. "Concentração da comunicação e os riscos à democracia no Brasil". In BERNARDO, Jonathan Hassen da Rocha. Comunicação e Direitos Humanos nos Territórios de Minas Gerais. MG: Associação Henfil Educação e Comunicação e Secretaria do Estado de Direitos Humanos, Participação Social e Cidadania, 2018.

BARRETO, C. Portaria 2016: o Al-5 da comunicação pública. Trincheiras. 15 abril 2109. Disponível em <https://medium.com/trincheiras/portaria-216-o-ai-5-dacomunica\%C3\%A7\%C3\%A3o-p\%C3\%BAblica-

72c0958132d9?fbclid=IwAR2QOAhoaDqES0S1C6yd2c7Z5RjbXgnCySCt4La0pd4VZjb23CuLFr Ke5NE>. Acesso em: 16 abril 2019

BAYMA, I. F. C. A concentração da propriedade dos meios de comunicação no Brasil. Eptic. Revista Electónica Internacional de Economía de las Tecnologías de la Información y de la Comunicación, v. 17, n. 3, pp. 140-172, 2001.

BRASIL. Constituição da República Federativa do Brasil. Brasília: Senado Federal, Coordenação de Edições Técnicas, 2016, 496p.

Medida provisória ${ }^{\circ} 870$, de 1 de janeiro de 2019. Diário Oficial da União, Atos do Poder Executivo, Brasília, DF, 1 jan. 2019. Seção 1 - Especial, p. 1-13

Lei n 9.612, de 19 de fevereiro de 1998. Institui o Serviço de Radiodifusão Comunitária. Diário Oficial da União. Atos do Poder Executivo, Brasília DF, 20 fev 1998, Seção 1, p. 11 
Decreto $\mathrm{n}^{\circ} 5.371$, de 17 de fevereiro de 2005. Aprova o Regulamento do Serviço de Retransmissão de Televisão e do Serviço de Repetição de Televisão. Diário Oficial da União. Atos do Poder Executivo, Brasília DF, 18 fev 2005, Seção 1, p. 1

Lei $\mathrm{n}^{\circ} 11.652$, de 7 de abril de 2008. Institui os princípios e objetivos dos serviços de radiodifusão pública explorados pelo Poder Executivo ou outorgados a entidades de sua administração indireta; autoriza o Poder Executivo a constituir a Empresa Brasil de Comunicação - EBC. Diário Oficial da União. Atos do Poder Executivo, Brasília DF, 8 abr 2008, Seção 1, p. 1

INTERVOZES; REPÓRTERES SEM FRONTEIRAS. Quem controla a mídia no Brasil? Intervozes - Coletivo Brasil de Comunicação Social, 2018. Disponível em < http://brazil.momrsf.org/br/>. Acesso em: 4 mar. 2019

INTERVOZES. Raio X da ilegalidade: políticos donos da mídia no Brasil. Observatório do direito à comunicação, 01 ago. 2016. Disponível em: < http://www.intervozes.org.br/direitoacomunicacao/?p=29753> Acesso em: 14 mar. 2019.

Sistemas públicos de comunicação no mundo: experiências de doze países e o caso brasileiro. São Paulo: Paulus, Intervozes, 2009 (Coleção Comunicação).

KUCINSKI, B.; LIMA, V. A. de. Diálogos da perplexidade: reflexões críticas sobre a mídia. São Paulo: Editora Fundação Perseu Abramo, 2009

LIMA, V. A. de. As bases do novo coronelismo eletrônico. Observatório da Imprensa. 08 ago. $2005 . \quad$ Disponível em: $<$ http://observatorio.ultimosegundo.ig.com.br/artigos.asp?cod=341IPB001>. Acesso em: 17 fev. 2019

MENDELL, T. Serviço público de radiodifusão: um estudo de direito comparado. Brasília: UNESCO, 2011. $104 \mathrm{p}$.

MORAES, D. de. Vozes abertas da América Latina: Estado, políticas públicas e democratização da comunicação. Rio de Janeiro: Mauad X: Faperj, 2011.

A batalha da mídia: governos progressistas e políticas de comunicação na América Latina e outros ensaios. Rio de Janeiro: Pão e Rosas, 2009.

MOTTER, P. A Batalha invisível da Constituinte: interesses privados versus caráter público da radiodifusão no Brasil. 1994. Dissertação (Mestrado em Ciência Política) - Universidade de Brasília, Conselho Nacional de Desenvolvimento Científico e Tecnológico.

PIERANTI, O. P. A radiodifusão pública resiste: A busca por independência no Brasil e no Leste Europeu. Brasília: FAC-UnB, 2018.

SANTOS, S. dos; CAPPARELLI, Sérgio. "Coronelismo, radiodifusão e voto: a nova face de um velho conceito". In: BRITTOS, Valério Cruz; BOLAÑO, César Ricardo Siqueira (Org.). Rede Globo: 40 anos de poder e hegemonia. São Paulo, 2005, v. 1, pp. 77-101.

SANTOS, S. dos. E-Sucupira: o Coronelismo Eletrônico como herança do Coronelismo nas comunicações brasileiras. E-Compós. Revista da Associação Nacional dos Programas de PósGraduação em Comunicação, pp.1-27, dez. 2006

TSE - Tribunal Superior Eleitoral. Eleições 2018: Justiça Eleitoral conclui totalização dos votos do segundo turno. Notícias TSE, 30 out. 2018. Disponível em < http://www.tse.jus.br/imprensa/noticias-tse/2018/Outubro/eleicoes-2018-justica-eleitoral-concluitotalizacao-dos-votos-do-segundo-turno >. Acesso em: 19 mar. 2019. 
VALENTE, J. 5 anos de Confecom: muito barulho por nada? Intervozes. 19 dez. 2014. Disponível em <http://www.intervozes.org.br/direitoacomunicacao/?p=28836>. Acesso em: 16 mar. 2019.

VILELA, P. R. "Democratização da comunicação - o que é?". In BERNARDO, Jonathan Hassen da Roch. Comunicação e Direitos Humanos nos Territórios de Minas Gerais. MG: Associação Henfil Educação e Comunicação e Secretaria do Estado de Direitos Humanos, Participação Social e Cidadania, 2018.

\section{O autor}

Professor do Departamento de Comunicação Social da Universidade Federal Fluminense (UFF). Doutor em Comunicação e Cultura pela Universidade Federal do Rio de Janeiro (UFRJ). E-mail: castilho.uff@gmail.com

Data de submissão: 28/04/2019

Data de aprovação: 03/11/2019 
